\title{
On Tourism English Translation in Cross-Cultural Communication
}

\author{
Wen Qin \\ Jiangxi Science \& Technology Normal University, Nanchang, 330013, China \\ shuimuxintaizi@163.com
}

Keywords: Cross-cultural communication; Tourism English; Translation; Communication.

\begin{abstract}
Cross-cultural communication is a phenomenon of interpersonal communication in different cultural backgrounds and has existed for a long time and is universal. There are obvious differences between Chinese and Western cultures. Therefore, many cultures with Chinese characteristics can be hardly understood by foreigners, and this is one of the most difficult problems in translation. The strategies to improve the translation of tourism English in cross-cultural communication mainly include appropriate translation of scenic spots, translation of historical figures by analogy, attaching importance to the principles of appropriateness and reciprocity, taking alienation as the main method and domestication as the supporting method while paying attention to Chinese cultural factors.
\end{abstract}

\section{Introduction}

With the rapid development of China's economy, tourism is also becoming internationalized. According to research, as early as in the late 20th century, more than 50 billion tourists came to China, and China's tourism industry is constantly developing and improving. The tourism industry creates an opportunity for exchange for people from different cultural backgrounds, but such exchange can only be accomplished with the help of suitable media. At present, cross-cultural communication is becoming increasingly important, which is also one important feature of an era. Translation is an important premise to realize cross-cultural communication. Tourism translators need to have a full understanding of the source language and when the Chinese tourism factors are converted into the target language, they must be accepted by the target language user. Thus, translation skills and cross-cultural communication awareness have already become a must requirement for the evaluation of translation workers.

\section{Study of Cross-Cultural Communication and Tourism English}

Cross-Cultural Communication Theory. The theory of cross-cultural communication was first proposed by the famous American cultural anthropologist Edward Hall in the book "Silent Language". Edward Hall believes that when people from different cultural backgrounds want to express their time, space or things, they often produce obvious differences. Cross-culture refers to the phenomenon of communication and exchange between people from different cultural backgrounds, which is long-standing and universal. In recent years, with the development of the tourism industry, research into cross-cultural communication has gradually become popular and become one of the cutting-edge academic research topics [1]. In the context of frequent international exchanges, the study of cross-cultural communication theory attracts more and more scholars, which also reflects the requirements and needs of the times to a certain extent. Cross-cultural communication, also based on cultural comparison, allows relevant scholars to understand the various differences generated in the communication between different cultures through a large number of data and cases so as to make people sensitive to cultural difference.

Connotations of Tourism English. Tourism is a form of cultural exchange, and the spread of our culture also needs to be achieved through the development of tourism. The dissemination of Chinese culture through tourism will help to not only attract foreign tourists, but also introduce foreign cultural information. Communication culture needs language media, so tourism English has become an important carrier of cultural exchange between China and the West. In other countries, the 
dissemination of human customs, habits, culture, information between different countries can help more in-depth exchanges, so tourism English is an important medium for cross-cultural communication. In the dissemination of culture, cultural exchanges and cultural integration, tourism English plays an important role. It can not help to reduce the difference between Chinese and Western cultures, but also promotes the publicity of Chinese culture. Tourism English is rich in cultural content, so it is necessary to pay attention to the accuracy of tourism English translation, and the language needs to be suitable for foreign tourists to read. For visitors to China, no matter what role they use to enter China, they have the same purpose: to enjoy the Chinese scenery and to understand the Chinese culture. Therefore, in the course of tourism English translation, this should be taken as a starting point to let foreign tourists easily realize their own tourism purposes, thus promoting international exchanges and cooperation [2]. Good tourism English translation with cross-cultural communication as the starting point can help foreign visitors understand the deep connotations of Chinese culture and become fond of the Chinese culture. In the process of translation, it is necessary to take the Chinese culture as the basic orientation, and publicize the excellent values and ideas of our culture to tourists, thus attracting foreign tourists. Language is the form of culture, which plays a significant role in cross-cultural communication, and can effectively bridge the communication between inside and outside.

Features of Tourism English Translation. The purpose of tourism also includes to understand the culture in addition to enjoying scenery at the destination. There is a close relationship between tourism and culture. The scenic spots contain beautiful natural scenery and magnificent cultural scenes, which are the most attractive factors for foreign tourists to come to visit. Tourism English translator needs to understand the local beauty and humanistic connotation through the language and make the translation easily understood by the English-speaking people, so as to attract foreign tourists to stop and visit. In addition, tourism English translation needs to be creative and well manifest the local characteristics with appropriate language organization. The translation should not only be appealing, but also excessively exaggerated. English is a global language and currently the most widely used language, so tourism English translation has an obvious role in promoting the development of China's tourism industry. In this context, the related research of tourism English translation materials has become a research focus of domestic tourism industry. It conforms to the requirements of the times with a very high demand. Tourism translation must be accurate and appropriate. In the process of translation, the translation should not deviate from the original meaning and must embody certain artistic value.

\section{Problems in Tourism English Translation in Cross-Cultural Communication}

With the deepening of international communication, the importance of English translation is gradually emerging. Tourism translation has become an indispensable means of communication in order to better promote international exchanges, deepen mutual understanding among countries and better promote local culture. English is the most influential language in the world at present. Therefore, the importance of English in tourism translation is self-evident. From the current situation of tourism English translation in cross-cultural communication, there are still obvious differences between Chinese and Western cultures, so many Chinese characteristics are not easily understood by foreign tourists. It is often difficult for translators to translate the translation accurately when they are translating to tourists, and because of the differences in logical thinking between Chinese and Western cultures, many of the essence of Chinese culture, such as poetry and song, can be hardly translated. It is hard to adopt literal translation to translation Chinese classical prose, otherwise, foreigners will not understand it [3]. In the process of tourism English translation, because the national material culture is different, it is difficult to find a lot of vocabulary translation method is accurate, if the words cannot be well understood, this translation will have a greater negative impact on intercultural communication. Tourism English translation in cross-cultural under communication is mainly to solve for communication barriers and cultural differences caused by the translation errors, and from this point of view, tourism English translation means the translation of the source language in the target language with foreign tourists' cross-cultural communication. In the process of translation, the translators must consider the issue from the perspective of communication cross-cultural, and the translated text generally contains abundant 
connotation, so in the process of translation, there is a need to show this connotation to foreign tourists for them to better understand Chinese culture, which also poses higher requirements for tourism English translation work.

\section{Strategies to Improve Tourism English Translation in Cross-cultural Communication}

Appropriate Translation of Scenic Spots. In the process of tourism English translation, when translators encounter the unique scenery or local culture, it is better not to use the literal translation to translate the names of these scenic spots' names because the translated version cannot reflect the original cultural mood and flavor, thus the final translation results cannot reflect local features. Particularly, in explaining the knowledge of tourism, literal translation should not be used to translate many Chinese unique cultural works, which may make it hard for foreign visitors to understand why these cultural works can last so long. In this regard, in the process of English translation, it is necessary to choose suitable translation strategies to achieve accurate translation of the scenic spots and attractions without losing the connotation and help foreign visitors to have a clearer and more profound understanding of Chinese culture. In the translation process, it is necessary to tell the significance of the tourist attractions and the stories behind them so as to really reflect the true significance of translation and allow tourists to personally feel the beauty of the scene.

Translation of Historical Figures with Analogy. Historical figures in ancient China are important targets for many foreign tourists to come to China, so correct interpretation of historical figures has always been the focus of translation. Of course, it is also the difficult point. In the context of cross-cultural communication, in the translation of tourism English, when translators encounter historical figures, they can explain to foreign visitors through analogy and compare the methods to describe culture in China and the West to make visitors have a clear picture of the figures while listening [4]. For example, to compare "Butterfly Love" with "Romeo and Juliet" and compare Confucius with Aristotle. In the translation of historical figures, it is necessary to list some similar classic foreign figures so as to deepen foreign visitors' understanding of these figures.

Pay Attention to the Principle of Suitability and Reciprocity. According to the present translation, it can be seen that there is a distinct difference between language and culture. Therefore, translation is unlikely to meet the requirements completely and cannot be translated in a comprehensive way. But translators can also innovate their translation methods when translating, and translate the text by using the principle of reciprocity and suitability. The reciprocity principle and the suitability principle refer to the functional equivalence in English translation, which requires that the translation needs to be as close as possible in many aspects [5]. Due to the existence of cultures, translators may encounter a lot of problems in tourism English translation, so the adoption of the principle of reciprocity and suitability can promote the accuracy of translation between two different cultures.

Take Alienation as the Main Translation Method and Domestication as the Supporting Method. "Domestication" is a kind of translation skill, which makes Chinese language characteristics basically disappear in the process of translation, but to gradually highlights the features of English is "domestication". The translation skills of "alienation" in the process of English translation are mainly to keep the characteristics of Chinese characters as far as possible. In the absence of appropriate expressions, the principle of "alienation" should be followed to promote better communication between Chinese and foreign countries. For example, as a symbol of China, the word "dragon" can't be accurately explained with English words, because the West's understanding of "dragon" is the exact opposite of Chinese. Therefore, in the process of tourism English translation, in order to explain the term "Four Asian Tigers", it can't be translated as "the Four dragons of Asia", which will bring very strange feeling to Westerners, so it is necessary to use "alienation" to translate it into "Four Tigers of Asia".

Consider the Chinese Cultural Factors. In the process of translation, it is necessary to have a more comprehensive understanding of Chinese cultural factors, and then the related factors of English culture need to be taken into account. Chinese cultural factors take the orientation of Chinese culture as the core. Therefore, in the process of tourism English translation, there is a need to publicize the Chinese culture 
and keep the essence as much as possible [6]. Also, there is a need to fully consider the characteristics of English culture. In the publicity of traditional Chinese culture, it is necessary to take the point of view of English culture as a starting point and translate according to the Westerners' mentality to make sure that foreigners cannot have ambiguous meaning to understand Chinese culture.

\section{Conclusions}

Generally speaking, there are many difficulties in tourism English translation in the context of cross-cultural communication, so translators should not only understand the English language, but also understand the relevant theoretical systems of the English culture. And they need to reflect the Chinese culture in translation to make the translation easily understood and accepted by foreigners and have a profound impression of Chinese culture.

\section{Acknowledgements}

This work is supported by the 2015 Social Science Planning Project (Research on Foreign Language Teaching in Jiangxi University): Research on Tourism Text Translation based on the Functional Theory(No.15WX312).

\section{References}

[1] P.Su. A Study on Cross-cultural Communication in Tourism English Translation, Economist, (2014) No.10, p.263-264.

[2] Y.N. Liu. On the Translation of Tourism English in Cross-cultural Communication, Science and Wealth, (2015) No.8, p.138-139.

[3] H.1. Yu. Tourism English Translation in the Context of Intercultural Communication, Selection of Small Writers (teaching exchange), (2014) No.8, p.215.

[4] Q.M. Zhang. An Analysis of the Obstacles and Strategies of Tourism English Translation from the Perspective of Intercultural Communication, New Campus (First Half), (2016), No.11, p.87.

[5] D. Guan. A Study on Tourism English Translation in Cross-cultural Communication, Wireless Internet Technology, (2014) No.11, p.134.

[6] F. Gu. A Study on Tourism English Translation from the Perspective of Cross-cultural Communication, Journal of Heihe University, (2016) No.8, p. 146-147. 